The concept of "pre-evaluative research" is examined in the context of a museum exhibition evaluation. Preevaluation research was recommended by some of the earliest writers in the evaluation field as a way of facilitating a formal, "ultimate," of summative evaluation. It is viewed as distinct from, and complementary to, an evaluability assessment. The exhibit preevaluative study indicates that instrumentation and implementation issues are likely to benefit from such activities, but that design and analysis may still suffer.

\title{
REVIVING PREEVALUATIVE RESEARCH
}

\section{An Illustration from the Arts}

\author{
PAUL M. WORTMAN \\ ROBERT W. MARANS \\ Institute for Social Research \\ University of Michigan
}

I

$\mathrm{n}$ his seminal volume on evaluative research, Suchman (1967) cited an early government monograph (Herzog, 1959) that introduced the concept of "pre-evaluative research." According to Suchman, such research "deals with the intermediate problems that need to be solved before one can attempt ultimate evaluation. These problems include the development of reliable and valid classifications of the problem, the definition of action goals, and the perfection of tools and techniques" (1967: 52). More recently Rutman $(1977,1980)$ has referred to this as "planning" and has added a variety of research design issues (such as internal and external validity) as additional concerns beyond specifying variables and developing measures.

AUTHORS' NOTE: This article is based on work performed under a 1983 National Endowment for the Arts grant. We wish to acknowledge the suggestions and assistance of Janet Landay and Jennifer Williams in conducting the study and in preparing this article, as well as the comments of two anonymous reviewers. 
Unlike Rutman (1980), however, preevaluative research is viewed as distinct in a number of important ways from other recent developments such as "evaluability assessment" (Wholey et al., 1975; Wholey, 1979). First, preevaluative research is primarily evaluation focused and not program focused. Its major purpose is to conduct preliminary work in developing an ultimate evaluation. As such, it is not aimed specifically at improving the program as in formative research (Scriven, 1972) nor in defining or modeling the ideal or "rhetorical" program as in evaluability assessment. Instead, preevaluative research moves beyond an analysis of the feasibility of conducting an evaluation to providing the actual elements for executing it. In that sense, it is an evaluation development phase rather than a planning phase that characterizes evaluability assessment.

Second, unlike evaluability assessment, preevaluative research is not specifically aimed at large government programs and their often distant managers, but, as in the present case, is useful in developing evaluations of "focal local" programs (Campbell, 1976) where there is a very close relationship of program and administration. Here programs are generally well-defined with goals and rationales that are readily available and agreed upon. In fact, preevaluative research assumes the evaluability of the program (just as Rutman, 1977: 25, does in his discussion of planning). It does this not by ignoring such issues as goal specification and hypothesis formation that are part of an evaluability assessment, but by going beyond this essential phase of program analysis. Thus, for example, the next section presents a modified evaluability assessment before describing the preevaluative research.

Third, preevaluative research focuses on the implemented or actual program. It therefore eliminates the need for constructing a rhetorical model that is the heart of evaluability assessment. Moreover, preevaluative research makes no concession to managers' or others' opinions concerning the ability to measure important goals and thus does not require developing an "evaluable" model either. If the goal is important enough and adequate resources are provided, it is the evaluator's task in a preevaluative study to provide acceptable measures. For example, in the community mental health center illustration of evaluability assessment provided by Wholey and his associates, only one of six goals or objectives is considered "ready for useful evaluation." This evaluable program model does not include the major goal of reducing the inappropriate use of state mental hospitals! Preevaluative research is not restricted by such circumstances, but through creative design and 
measures can capture this objective (see McSweeney and Wortman, 1979). In the present preevaluative study, critical goals were not omitted and design options were developed for evaluating secondary objectives.

Finally, preevaluative research is an active process involving data collection and analysis, whereas-as Rutman (1977: 57) notesevaluability assessment is largely a passive analytic and archival process. One way preevaluative research accomplishes this is by focusing on well "articulated" (Rutman, 1977), strongly implemented (Sechrest et al., 1979) variants of the program. For example, in the present study one exemplary site was selected for more intensive study in order to develop measures of important objectives identified by an evaluability assessment.

Preevaluative research is especially useful in times or areas of fiscal constraint such as the current U.S. climate of fiscal austerity that does not favor investment in social innovations and their formal evaluation. Preevaluative research may be viewed as a cost-effective alternative strategy for assessing agency-sponsored programs. For a small investment it can quickly provide information on the design and conduct of a more formal evaluation. In the present study, for example, a small (less than $\$ 25,000$ ) National Endowment for the Arts grant enabled the program staff, working with the authors, to conduct preevaluative research and to develop an approach that could be used in evaluating a program on an ongoing basis.

Preevaluative research should include options for alternative measurement procedures and research designs and their associated costs. Such a study could be used by the agency to make a stronger case for undertaking an "ultimate" evaluation or to indicate a more costeffective way of conducting the evaluative study. Moreover, by attending to issues concerning evaluative objectives, proper measurement, design, and analysis, preevaluative research can speed the completion of the formal evaluation study that follows and, it is hoped, improve the likelihood of its utilization if timeliness (Weiss, 1977) and stakeholder needs (Wiess, 1983) are, in fact, relevant. It also can avoid the conflict over the control of the study inherent in the use of external evaluators while reducing problems associated with internal evaluators (see Campbell, 1979). By giving the sponsor control or "ownership" of the evaluation, a preevaluative research study is much more likely to enhance utilization.

This article illustrates the potential of preevaluative research by presenting an example drawn from the arts - a museum exhibition 
program. It is divided into five parts. In the next part, a brief evaluability assessment of the program is presented followed by $\mathbf{a}$ review of the purposes of the preevaluative study, the approach used, and the constraints under which the study was conducted. The third part of the article describes the preevaluative methods including preliminary field investigations, which served as a prelude to a preevaluative pilot study. The fourth part discusses the results. Based on those results, several recommendations for conducting a formal evaluation of the program are presented in the final section, along with a discussion of how those recommendations were used.

\section{MODIFIED EVALUABILITY ASSESSMENT}

A modified evaluability assessment is necessary to identify plausible, measurable hypotheses that are to be the focus of the preevaluative research. As noted earlier, this requires a description of the program and its purposes. It also includes the elimination of unimportant and untestable hypotheses derived from goals considered of secondary or lesser importance. In addition, it should include where possible hypotheses of scientific interest to the evaluators (Rutman, 1977).

\section{PROGRAM AND PURPOSES}

The first step was to understand the evaluative objectives of the program's staff, and their concept of its purposes or objectives. The program under consideration was developed by one of the nation's largest museums. It was an outreach activity providing several art exhibits to high schools throughout a midwestern state. The initial exhibits covered historically significant architectural monuments (such as the Roman Colosseum) and each contained a scale model of the monument and 20-25 mounted panels containing drawings, photographs, and textual material. A major objective of the museum was to foster an interest in the arts and an awareness of the resources of the museum among high school students. The program's administrative staff was particularly interested in students' cognitive and affective reactions to the exhibits.

Recently the museum has developed other exhibits that do not use the model format and that are based on materials contained in their own 
collection. The new exhibits are composed solely of panels containing thematically related material. At the time of this study, the first of these exhibits, covering the Renaissance period, was being introduced. To a lesser extent the museum wanted information about the market potential of the new exhibits made up solely of panels.

All exhibits are made available to high schools through a statewide distribution network. The various network offices are responsible for distributing educational materials to schools and school districts within their region. Materials such as the museum exhibits are loaned to media specialists (or librarians) of the high schools for a limited period. In the present case, schools typically displayed the exhibits for one week.

Once the program's objectives had been obtained and discussed with the museum's staff, the following four preliminary hypotheses were derived:

(1) The exhibits will increase students' knowledge.

(2) Students will like the exhibits and become interested in visiting museums.

(3) The model is not critical to the effectiveness of the exhibit (as tested in hypotheses 1 and 2).

(4) The context or physical layout of the exhibit will moderate its effectiveness (as tested in hypotheses 1 and 2).

The last hypothesis represented our own interests in built environments and their impact on human behavior. One of us (RWM) is an architect who has conducted extensive research in this area.

A meeting with the administrative staff of the local network office revealed that they were unaware of the new Renaissance exhibit. It was clear that the volume of other business made it difficult for the museum to market new exhibits through the network offices or to enlist their cooperation in participating in an evaluation. Moreover, phone conversations with the media specialists scheduled to display an exhibit at their schools also confirmed their lack of awareness of an interest in the new Renaissance exhibit. As a consequence of this situation and the lesser importance of the goal, it was decided that hypothesis 3 should be dropped from the preevaluative study since no field data were obtainable on the new exhibit format. However, some design options for conducting such an evaluation were prepared.

The modified evaluability assessment revealed that only the modelbased exhibits were evaluable. Archival information indicated that the exhibits had been widely circulated to schools throughout the state in preceding years. Moreover, conversations with media specialists indi- 
cated that the models were to be exhibited at a number of schools in the immediate area. Three specific hypotheses were deemed evaluable and preevaluative research was undertaken to examine the implemented program and to develop a design and instruments to assess it.

\section{PREEVALUATIVE RESEARCH METHODS}

The approach taken in the preevaluation research study was both exploratory and interactive. The initial step of preevaluative research is for the evaluator(s) to gain a firsthand understanding of the program itself. This was accomplished by visits to a number of schools to meet with school personnel and to observe the exhibits and the activities associated with them, and by a review of the literature on museum evaluations. ${ }^{1}$

The small amount of funds available for preevaluative research will necessarily limit access to the program sites. In the present case the field investigations were conducted at nearby schools participating in the exhibit program. During the school year the local distribution office had available the new exhibit on the Renaissance as well as the "Ancient Arena: The Roman Colosseum" that used the model-based format. Access to important program variations or components is an important concern in preevaluative research. The availability of both types of exhibits was not viewed as restrictive in this case. ${ }^{2}$ Our plan involved first obtaining the exhibit schedule and then contacting by telephone all media specialists planning to use one of the two exhibits.

\section{SITE VISITS}

Based on the phone conversations and the schedule, three sites were scheduled for visits. One high school media specialist indicated she had considerable experience with other model-based museum exhibits and had developed a number of ancillary materials to augment the current exhibit. Her school was selected for a site visit. Two other schools scheduled for the exhibit were also visited. The media specialists at these schools were interviewed and the exhibit was photographed. As noted earlier, one of the objectives of preevaluative research is to identify sites where the program has both "strength and integrity." These field observations led to the decision to conduct a preevaluative pilot study at 
one of these high schools where the program was particularly well articulated and well implemented.

\section{PILOT STUDY}

A major purpose of preevaluative research is to develop measures of program objectives. A pilot study was conducted to field test some instruments developed for the evaluation. The instruments were aimed at three of the major stakeholders and targets of the program - teachers, students, and media specialists. The preevaluative pilot study consisted of two parts: class-administered questionnaires to students and questionnaire-guided personal interviews with teachers. ${ }^{3}$ Both the student and teacher questionnaires contained similar questions evaluating the exhibit. In addition, the student questionnaire repeated factual questions from a worksheet prepared by a media specialist and used by the students at the time they viewed the exhibit two months earlier.

\section{RESULTS}

This section presents findings from the site visits to the three high schools and the pilot study. It then outlines a number of recommendations made to the museum for modifying the existing exhibit program, for planning new exhibits, and for conducting formal evaluations in the future.

\section{SITE VISITS TO SCHOOLS}

The exhibit was set up in the library or media center of all three schools visited. The media center of the first school was a modern, spacious wood-paneled room ideal for a model-based exhibit such as the Roman Colosseum. The room contained a depressed central circular area that was used to display the entire exhibit. This area was surrounded by a railing on which the panels were hung. The students could thus circulate around the periphery of this enclosure and view the entire exhibit.

The media specialist did not prepare any additional materials to be included with the exhibit. She viewed her job as setting up the exhibit, 
bringing it to the attention of teachers and community groups, and scheduling times when classes could view it. Classes studying ancient history, mythology, art, and Latin viewed the exhibit on the day of our visit. Most teachers did not attempt to organize their students' time at the exhibit. Consequently, many students "breezed through" it and spent the rest of class period chatting with friends or browsing through other library material. All the teachers were enthusiastic about having such an exhibit available in the school, especially given the elimination of funds for off-campus field trips. With but a few exceptions, they had made some effort to incorporate the exhibit into their classroom lessons.

At the second school, the media specialist took an entirely different approach to the exhibit. She tried to simulate an actual museum by placing the display panels on the walls of three different rooms in the library. She also supplemented the exhibit with other materials including a 10-minute film on ancient Roman culture that the students viewed prior to visiting the exhibit. The display panels were interspersed with quotes from Mark Twain's "Innocents Abroad" and a table with books on ancient Rome was available for interested students.

Despite the additional materials and organizational effort by the media specialist, the students approached the exhibit in the same manner as students at the first school. Most hurried through spending only 10 minutes examining the exhibits. One class, however, was required to write an essay on the exhibit and spent considerably more time viewing it.

At the third school, the media specialist supplemented the exhibit with a display case outside the library featuring the Colosseum exhibit, a brief five-minute introductory lecture, a film on ancient Rome, worksheets containing questions derived from each of the exhibit panels, a map indicating the location of Rome, and a display of books on ancient Rome.

The highly structured and diversified approach used at the third school was further developed by dividing each class into two groups. The media specialist accompanied one group in examining the model while students in the other group circulated around the panels writing answers to questions on the worksheets. Teachers then collected and graded the worksheets and discussed them in classes the next day. Most students spent the entire 50-minute class period examining the exhibit.

It is important to reappraise goals and hypotheses constantly during the course of preevaluative research. This is formative research that is 
applied to the evaluation rather than the program. In the present case, the site visits made clear that the physical layout or context of the exhibit was not a critical antecedent variable. The site with clearly the best physical layout received the least student attention, whereas the exhibit site with the worst achieved high student participation. Given the considerable educational and psychological research indicating the relationship between time on task and learning, it was clear that context was not sufficient to attract student attention. Instead, additional program components such as the study guide used at the third site would be necessary. As a consequence, context was dropped from the study.

\section{PILOT STUDY}

As was indicated earlier, the display of the Roman Colosseum exhibit at the third school was well implemented, and with the additional materials represented a "strong treatment." Since one of the museum's major objectives in the evaluation was to assess learning, this site presented an opportunity to measure students' long-term retention and, most important for the preevaluative research, to develop and test questionnaires that might eventually be used in the more formal evaluative study. Arrangements were made to return two months later to the school to conduct a preevaluative pilot study.

\section{Student Questionnaires}

Questionnaires were administered to a total of 91 students in five classes. To measure student learning (see hypothesis 1), 13 questions from the worksheets were included in the questionnaires. Originally the five classes had answered between $82 \%$ and $92 \%$ of the questions correctly. Two months later there was much more variation with the retention rate for the five classes ranging from $36 \%$ to $67 \%$ with a weighted average of $53 \%$. These results indicated that the instrument would provide a useful measure of learning with the addition of a suitable pretest. ${ }^{4}$

In addition to factual information, the questionnaire obtained students' subjective impressions of the exhibit as a learning experience to further assess hypothesis 2 . They were asked to indicate how much they thought they learned from the exhibition, how much they liked the 
exhibition, and the degree to which they felt it was worthwhile. The vast majority of students (92\%) said they would like to see more such exhibits come to their school and thought the Colosseum exhibit was worthwhile.

The questionnaires also contained items measuring students' interest in the arts, their awareness of the museum's sponsorship, their assessment of the amount of time spent viewing the exhibit, their interest and actual experiences in viewing other exhibits, and related background information to test part of hypothesis 2 . Responses to those items and the complete questionnaire are presented in the final report (Marans and Wortman, 1984).

\section{Teacher Interviews}

Structured interviews based on a questionnaire were conducted with the five teachers whose classes viewed the Colosseum exhibition. These interviews revealed that teachers devoted about 25 minutes on average to preparing their classes for the exhibition prior to visiting the library. Three of them incorporated material from the exhibition into their regular class work. The other two said that it did not fit in with their lesson plans.

All five teachers were enthusiastic about the exhibition and felt that it was very worthwhile. They mentioned the model, exposure to a foreign culture, the film, and the opportunity to discuss the present as it relates to the past. The least worthwhile aspect of the exhibit was the amount of reading material presented on the panels.

Teachers were less enthusiastic about student responses to the exhibition. Only one felt that the students learned "a lot." The teachers felt the students liked the model, the film, and the particular subject matter.

The teachers also answered questions about the number of classes, grades, time spent viewing the exhibit, use of background materials provided by the museum, and other aspects of the exhibit. Each of them readily volunteered comments and suggestions for the museum regarding the future of the exhibition program. They were interested in having other exhibitions at the school, especially since the district's travel funds had been greatly curtailed. Four of the five teachers were interested in having an exhibit about the Renaissance, although none had heard of it. 


\section{RECOMMENDATIONS}

Based on the pilot study and our earlier site visits, we were able to make several formative recommendations to the museum staff for strengthening the exhibit program in addition to those for formally evaluating it on an ongoing basis. Formative program recommendations for improving and strengthening the exhibit program covered a number of general evaluative issues such as procedures for publicizing the program (such as announcing its availability through direct mailings to media specialists); for assuring its integrity (for example, through the use of instructional guides for setting up exhibits); and for strengthening it (for instance, augmenting the exhibits with resources from the local distribution office). It also included some strategic formative recommendations including pilot testing (such as showing exhibits at selected schools prior to circulating them throughout the state) and stakeholder assistance in program design (for example, by using the experiences and skills of local media specialists).

Since the major purpose of preevaluative research is the conduct of an ultimate evaluation, an extensive set of recommendations was proposed for conducting such an evaluation. As with most evaluations, the recommendations dealt with issues of implementation (the manner in which exhibits are displayed and used); the attitudes of major participants and recipients (students', teachers', and media specialists' reactions to the exhibits); important impacts (the amount and nature of learning on the part of students); and some long-term effects (students' subsequent behaviors with respect to pursuing an interest in the arts). In order to evaluate these objectives, it was proposed that information covering each exhibit be collected from relevant participants at each site. Specifically, it should be obtained from the three sources noted above: the media specialist at the school receiving an exhibit, the teachers within that school whose classes have viewed the exhibit, and the students whose classes have seen the exhibit.

\section{Methodology and Data Requirements}

Preevaluative research requires the specification of a design and analysis plan. The basic design methodology recommended for evaluating each exhibit was a systematic, statewide survey of the three key users. In particular, it was suggested that survey data be obtained 
through mailed, self-administered questionnaires distributed to individuals who participated in the exhibit program. This would lower costs considerably, but at the risk of a lowered response rate. A sampling scheme for selecting schools would be developed from an exhibit's travel schedule. Since the distribution offices vary in geographic location and represent school districts and schools that vary in size, type of service area (urban/rural), and socioeconomic status of the student body, it was recommended that the evaluation be conducted in at least three of the state's regions and include at least two schools within each region. Versions of the teachers' and students' questionnaires developed and pretested in the preevaluative pilot study would be used. A media specialist questionnaire would be developed and pretested before being used in a statewide evaluation.

The pilot work indicated that the cooperation of the media specialists within the schools displaying the exhibits was crucial to obtaining useful data. Accordingly, a number of specific steps were recommended to facilitate the data collection phase of a formal evaluation. These included obtaining the names and telephone numbers of the media specialists from the director of the regional distribution office, prior telephone contact with the media specialists, and detailed instructions covering procedures for conducting the evaluation. It was also recommended that the teachers be given responsibility for administering and collecting student questionnaires. Similarly, media specialists would be responsible for collecting packets of completed questionnaires from the teachers in their schools.

A second major part of the preevaluative methodology involves data analysis. It was proposed that a detailed analysis plan be developed by the museum staff working in close collaboration with a data analyist. ${ }^{5}$ The analysis plan would specify information to be extracted from the data, such as the following: What proportion of students throughout the state found an exhibition worthwhile? What is the average length of time teachers spent in preparing classes for viewing the exhibition? What is the average proportion of correct answers on the factual questions scored by students in different parts of the state?

As suggested earlier, it was possible to explore relationships between responses from one set of questionnaires and those of another. For instance, museum staff could determine the degree to which teachers' perceptions of student learning correspond with students' perceptions of what they thought they learned and what, in fact, the students actually learned (as measured by the test scores). Similarly, the strength of the 
treatment (as measured by the media specialist responses) could be examined in relation to its impact (that is, student learning). The data available form the three sets of questionnaires would enable the museum's program staff to consider any number of possible relationships (hypothesis testing) and address questions important to the overall exhibit program.

\section{Alternative Evaluation Designs}

Preevaluative research should include alternative designs, methods, and analyses. It was noted that a decision would be required regarding the evaluation research design and the quantity of data that the museum would collect and analyze. To a large extent, that decision would be based upon the staff time available for carrying out the evaluation and the funds available for conducting the work. Six alternative survey sampling plans were proposed for evaluating any single exhibit during a single year (see Table 1). For each plan, information was given on the number of regions (distribution offices) to contact, the number of schools within each region for which data would be collected, the number of teachers in each school, and the number of classes of each teacher that would be administered questionnaires.

It was suggested that additional plans that produced larger or smaller numbers of respondents in the three groups could be developed. The major advantage to the smaller numbers would be the savings of time and money. The major disadvantage would be the inability to conduct a meaningful analysis of media specialist and teacher responses. The museum was informed that should any one of the plans be implemented for more than a single exhibit, then comparative quasi-experimental assessments of exhibits could be made yielding better information with which to modify current exhibits and design new ones. For instance, if plan $\mathrm{C}$ were used to evaluate both the Colosseum and the Renaissance exhibits during a given year, the museum's staff would be able to judge the relative strengths and weaknesses of each exhibit and then take appropriate actions to improve their effectiveness in achieving exhibit goals.

\section{Alternative Evaluation Approaches}

Preevaluative research should provide program administrators with alternative evaluation approaches should they decide that the program 


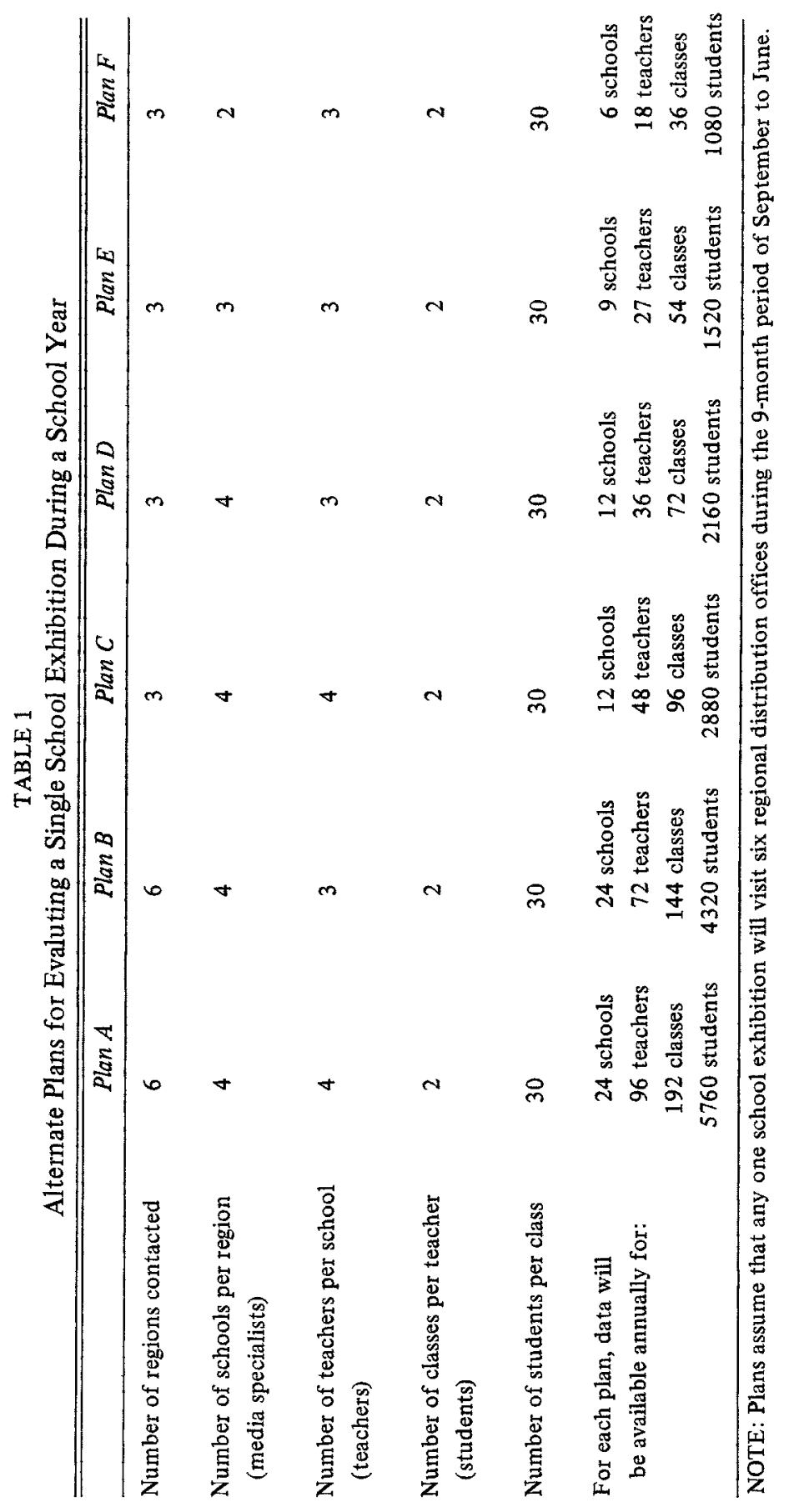


is not sufficiently "debugged" (Campbell, 1984) or at a "climax" stage (Tharp and Gallimore, 1979). If a statewide evaluation based on surveys of media specialists, teachers, and students was not possible or was judged to be premature, it was recommended that the museum conduct a more focused local evaluation in a few schools using a quasiexperimental design approach. Information obtained from such an approach could produce useful insights and tests of specific hypotheses. For example, with the selection of appropriate control schools, student learning as a function of treatment strength could be assessed.

Although such designs are attentive to internal validity issues, museum staff was reminded that findings from such a study could not be generalized beyond the one or two schools under investigation. That is, major changes in an exhibit based on the results of a study conducted at a few schools would be unwise. If, on the other hand, the changes were viewed as a "trial modification" or formative evaluation of program components (Boruch, 1976), and efforts were made to assess their impact on students and teachers, this incremental approach to improving the exhibition program could be considered a viable alternative to the statewide approach.

Still another compromise evaluation strategy recommended involved the collection of information via surveys only from media specialists and/or teachers whose classes had seen an exhibit. The museum staff was informed that this approach would not give them information about students and their responses to the program, but that it could yield data that could influence marketing strategies, exhibit design, or exhibit distribution. Finally, recommendations for taking a mixed approach were made involving a selected sample of media specialists and teachers and, from among the latter, questionnaires administered to only a few classes.

\section{UTILIZATION OF THE PREEVALUATIVE STUDY}

It is important to assess the value of preevaluative research studies just as it is for the ultimate evaluative studies. This has typically been done by examining utilization. Although one case is far from definitive, it can be instructive. This section presents a brief description of the use of the preevaluative research study by the museum's staff.

Following a review of the recommendations from the preevaluative study, the museum's staff decided to modify the procedures for 
disseminating information about the exhibit program and to conduct a formal evaluation of the Renaissance and Colosseum exhibits during the next school year. Regarding dissemination procedures, they clarified and expanded the explanatory material that accompanied each exhibit. Included in this material was a detailed set of instructions covering the installation of the exhibit. They also initiated direct communications with media specialists by mailing each member of the state media specialist's association a flyer describing the exhibits, and by attending their annual conference where they presented an overview of the exhibit program.

Limited resources precluded the museum's staff from following any of the recommended survey plans for conducting a statewide evaluation of its exhibits. Instead, they adopted a strategy for soliciting evaluative and factual information from schools throughout the state using the three questionnaires developed as part of the preevaluative study. The names of the media specialists who were scheduled to receive an exhibit were obtained from the regional distribution network offices. Each was contacted by telephone and then by letter to elicit their participation. Only 20 of 41 media specialists responded and of these only 17 were willing to cooperate in the evaluation. The remaining specialists were willing to complete the questionnaire but did not want to involve teachers and students in the evaluation.

The media specialists distributed packages of student and teacher questionnaires in each of the 17 schools. Most of these schools (13) had viewed the Colosseum exhibit. By the end of the school year, the museum had collected and coded questionnaires from these schools and conducted the preliminary computer runs to determine how teachers and students evaluated both exhibits. The preliminary findings and the experience of using standardized questionnaires also prompted the museum's staff to prepare questionnaires that will be used in evaluating other exhibits.

In conclusion, the utilization of the preevaluative research indicates both the potential and limitations of this approach. On the positive side, preevaluative research provided some useful formative information and allowed for the development of instruments specifically tailored to the objectives of the program administrators. The latter typically has not been done in evaluation research and has led to problems in reaching an assessment of innovative programs (see Anderson et al., 1978; House et al., 1978). On the negative side, the evaluation team can still not be sure that a strong research design will be used or that treatment implementa- 
tion issues will be fully addressed. The media specialists' questionnaire did provide information on implementation, however, that could permit more fine-grained analysis. The museum staff did not choose to consult with us before conducting their ad hoc survey so there was little opportunity to affect their evaluative decisions other than through the recommendations and advice offered in our original report. Clearly, evaluators undertaking such preevaluative studies must be aware of these risks and communicate them effectively. Even so, the transfer of ownership of the evaluation inherent in this approach carries with it the risk that the evaluation will not be properly implemented.

\section{NOTES}

1. A review of the literature in evaluation research and the arts was unable to find any reported studies dealing with the evaluation of similar museum exhibitions or programs (see Screven, 1984; Hicks, 1986). The literature suggests that curators and exhibition designers have been conducting evaluations of exhibits and museum space that focus either on its physical elements such as lighting and signage or visitor reactions (Eason and Linn, 1976; Griggs, 1981; Greenglass and Abbey, 1981; Landay and Bridge, 1982). Evaluation activities are currently undergoing a renaissance in the museum field with terms like audience research, visitor surveys, market studies, and needs assessment becoming part of the everyday vocabulary of professionals (Hood, 1986; Munley, 1986). Whether the concept of preevaluative research emerges as a viable activity among these museum professionals remains to be seen.

2. As noted in the preceding section, the new Renaissance exhibit was not scheduled to be shown in the local area. This was of some concern to the museum staff. Later they decided to visit a distant school and administer a variant of the preevaluative measures we prepared.

3. Since there was only one media specialist, we had a long talk with her and used this information, along with points made in other conversations with her and other media specialists, to develop a questionnaire.

4. The lack of a pretest, however, made it impossible to know how much of the retained information represented new knowledge learned from the exhibit.

5. The museum staff had made arrangements to have the data analyzed at a local university. We were prepared to provide additional assistance if requested.

\section{REFERENCES}

ANDERSON, R. B., R. G. ST. PIERRE, E. L. PROPER, and L. B. STEBBINS (1978)

"Pardon us, but what was that question again? A response to the critique of the Follow Through evaluation." Harvard Educ. Rev. 48: 161-170. 
BORUCH, R. F. (1976) "On common contentions about randomized field experiments," in G. V Glass (ed.) Evaluation Studies Review Annual, vol. 1. Beverly Hills, CA: Sage. CAMPBELL, D. T. (1976) "Focal local indicators for social program evaluation." Social Indicators Research 3: 237-256.

CAMPBELL, D. T. (1979) “Assessing the impact of planned social change." Evaluation Program Planning 2: 67-90.

CAMPBELL, D. T. (1984) "Can we be scientific in applied social science?" in R. F. Conner et al. (eds.) Evaluation Studies Review Annual, vol. 9. Beverly Hills, CA: Sage.

EASON, L. P. and M. LINN (1976) "Evaluation of the effectiveness of participatory exhibits." Curator 19: 45-62.

GREENGLASS, D. and O. ABBEY (1981) "An analysis of visitors' reponses to objects in a traveling exhibition." Curator 24: 181-188.

GRIGGS, S. A. (1981) "Formative evaluation of exhibits at the British museum." Curator 24: 189-202.

HERZOG, E. (1959) Some Guide Lines for Evaluative Research. Washington, DC: U.S. Department of Health, Education and Welfare, Chidren's Bureau.

HICKS, E. (1986) "An artful science: a conversation about exhibition evaluation." Museum News 64: 32-39.

HOOD, M. (1986) "Getting started in audience research." Museum News 64: 24-31.

HOUSE, E. R., G. V GLASS, L. D. McLEAN, and D. G. WALKER (1978) “No simple answer: critique of the Follow Through evaluation." Harvard Educ. Rev. 48: $128-160$.

LANDAY, J. and G. BRIDGE (1982) Video vs. wall-panel display: an experiment in museum learning." Curator 25: 41-56.

MARANS, R. W. and P. M. WORTMAN (1984) An Approach to Evaluating the Detroit Institute of Arts' Statewide Services Traveling Exhibition Program. Ann Arbor, MI: Institute for Social Research.

McSWEENEY, A. J. and P. M. WORTMAN (1979) "Two regional mental health treatment facilities: a reanalysis of evaluation of services." Eval. Q. 3: 537-556.

MUNLEY, M. E. (1986) "Asking the right questions: evaluation and the museum mission." Museum News 64: 18-23.

RUTMAN, L. (1977) "Planning an evaluation study," in L. Rutman (ed.) Evaluation Research Methods: A Basic Guide. Beverly Hills, CA: Sage.

RUTMAN, L. (1980) Planning Useful Evaluations: Evaluability Assessment. Beverly Hills, CA: Sage.

SCREVEN, C. G. (1984) "Educational evaluation and research in museums and public exhibits: a bibliography curator." 27: 147-165.

SCRIVEN, M. (1972) "The methodology of evaluation," in C. H. Weiss (ed.) Evaluating Action Programs: Readings in Social Action and Education. Boston: Allyn \& Bacon.

SECHREST, L., S. G. WEST, M. A. PHILLIPS, R. REDNER, and W. YEATON (1979) "Introduction," in L. Sechrest (ed.) Evaluation Studies Review Annual, vol. 4. Beverly Hills, CA: Sage.

SUCHMAN, E. A. (1967) Evaluative Research. New York: Russell Sage.

THARP, R. G., and R. GALLIMORE (1979) "The ecology of program research and evaluation: a model of evaluation succession," in L. Sechrest et al. (eds.) Evaluation Studies Review Annual, vol. 4. Beverly Hills, CA: Sage.

WEISS, C. H. [ed.] (1977) "Introduction," in Using Social Research in Public Policy Making. Lexington, MA: D.C. Health. 
WEISS, C. H. (1983) "The stakeholder approach to evaluation: origins and promise," in A. S. Bryk (ed.) Stakeholder Based Evaluation: New Directions for Program Evaluation, no. 17. San Francisco: Jossey-Bass.

WHOLEY, J. S. (1979) "Evaluability assessment," in L. Rutman (ed.) Evaluation Research Methods: A Basic Guide. Beverly Hills, CA: Sage.

WHOLEY, J. S., J. N. NAY, J. W. SCANLON, and R.E. SCHMIDT (1975) “If you don't care where you get to, then it doesn't matter which way you go," in G. M. Lyons (ed.) Social Research and Public Policies. Hanover, NH: University Press of New England.

Paul M. Wortman is Professor in the School of Public Health and Research Scientist at the Institute for Social Research, both at the University of Michigan-Ann Arbor. His current research interests are evaluation research methods and medical technology assessment.

Robert W. Marans is Professor in the College of Architecture and Urban Planning and Research Scientist at the Institute for Social Research, both at the University of Michigan-Ann Arbor. His primary research interest is in the evaluation of built environments. 